\title{
Human drug metabolism genes in parathion- and estrogen-treated breast cells
}

\author{
G.M. CALAF ${ }^{1,2}$ and D. ROY ${ }^{3}$ \\ ${ }^{1}$ Instituto de Alta Investigación, Universidad de Tarapaca, Arica, Chile; \\ ${ }^{2}$ Center for Radiological Research, Columbia University Medical Center, New York, NY; \\ ${ }^{3}$ Department of Natural Sciences, Hostos College of the City University of New York, Bronx, NY, USA
}

Received July 19, 2007; Accepted August 28, 2007

\begin{abstract}
Environmental chemicals may be involved in the etiology of breast cancer. Among them, organophosphorous compounds are the most widely used pesticides because of their extensive use in agriculture, medicine and industry. The risk of breast cancer is associated with prolonged exposure to female hormones and is attributed to estrogen since prolonged stimulation by steroid hormones may increase cell division. The aim of the present study was to identify the differentially expressed genes encoding enzymes that are important to drug transport and metabolism in parathion- and estrogen-treated human breast epithelial cell lines using cDNA microarrays. MCF-10F, an immortalized human breast epithelial cell line was treated with parathion and estrogen, either alone or in combination, and malignant cells were developed through a series of sequential steps. Differential expression from the drug metabolism gene array showed that 17 genes were found to be altered either by parathion or estrogen alone, or the combination of both. Among the genes altered by parathion in comparison to the control were CHST5, CHST6 and CHST7 (sulfotransferases); CYP2F1, CYP3A7 and CYP4F3 (CYPs); GSTP1, GSTT2 and MGST1 (GSTs); MT1X (metallothionein); TPMT (methyltransferase); UGT1A1 and UGT2B (UDP glycosyltransferases). The same genes were down-regulated in estrogen alone including several metallothioneins (MT1A, MT1E, MT1H, MT1L and MT2A). The combination of parathion and estrogen induced downregulation of three sulfotransferases, CYP2F1 and CYP4F3, MGST1, all metallothioneins and TPMT genes. There was no change in CYP3A7, GSTP1, GSTT2, UGT1A1 and UGT2B genes in the presence of both substances. It can be concluded from this study that organophosphorous pesticides such as parathion in the presence of estradiol induced
\end{abstract}

Correspondence to: Dr Gloria M. Calaf, Instituto de Alta Investigación, Universidad de Tarapaca, Calle Antofagasta \#1520, Arica, Chile

E-mail: gmc24@columbia.edu

Key words: drug metabolism genes, parathion, estrogen, breast epithelial cells changes in human drug metabolism gene expression in breast cells.

\section{Introduction}

Environmental chemicals may be involved in the etiology of breast cancer (1-3). Organophosphorous compounds are the most widely used pesticides by virtue of their biodegradable nature and short persistence. Such compounds are of great interest because of their extensive use in agriculture, medicine and industry. Pesticides seem to be serious threats to humans (4-9). The relationships between chemical pesticides and the incidence of cancer have been previously reviewed (7). The organophosphorous compounds are causally linked with nonHodgkin's lymphoma and leukemia (8). In animal studies, many pesticides have been proven to be carcinogenic; e.g., organochlorines such as DDT, chlordane and lindane are tumor promoters (8). On the other hand, the risk of breast cancer is also associated with prolonged exposure to female hormones (10-13). Among these hormonal influences, a leading role is attributed to estrogen since prolonged stimulation by steroid hormones may increase cell division, increasing the risk of breast cancer (10-13).

Differential expression from the drug metabolism gene array includes functional gene groups related to Drug transporter such as metallothioneins and P-glycoprotein family; Phase I metabolizing enzymes such as cytochrome P450 (CYPs) and Phase II metabolizing enzymes such as acetyltransferases, epoxide hydrolases, glutathione Stransferases (GSTs), methyltransferases, sulfotransferases and UDP glycosyltransferases (14-18). Metallothionein (MT) is a sulfhydryl- and cysteine-rich protein found in microorganisms, plants and all invertebrate and vertebrate animals (14). MTs are a group of ubiquitous low-molecular-weight proteins that have functional roles in cell growth, repair and differentiation. MTs are implicated primarily in metal ion detoxification, as they are essential for the protection of cells against the toxicity of cadmium, mercury and copper. MT is a stress-response protein and free radical scavenger and it is related to inflammation and cellular protection from reactive forms of oxygen, ionizing radiation, pharmacological agents and mutagens (14).

Human cytochrome P450 2E1 (CYP2E1) is a Phase I metabolizing enzyme. It is involved in the biotransformation 
of xenobiotics and endogenous substrates (15). Interindividual genetic polymorphisms of the CYP2E1 gene are associated with different cancer diseases. Mammalian cytosolic GSTs form a super family consisting of four distinct families, named $\alpha, \mu, \pi$ and $\theta$. The $\mu$ (GSTM1) and $\theta$ (GSTT1) members of the GST multigene family are candidate cancer susceptibility genes because of their ability to regulate the conjugation of carcinogenic compounds to excretable hydrophilic metabolites (16-18). Worldwide, organophosphate insecticides result in numerous poisonings each year. The organo(thio)phosphate esters are one of the most widely used classes of insecticides. In insects, GSTs play an important role in insecticide resistance. GST enzymes mediate exposure to cytotoxic and genotoxic agents and may be involved in cancer susceptibility (14-18).

An in vivo rat mammary tumor model has already been established induced by eserine and the organophosphorous pesticides parathion and malathion, possibly through acetyl cholinesterase inhibition (19) and by $17 ß$ estradiol (20). The identification of factors involved in cell proliferation and transformation has been facilitated by in vivo studies as well as in vitro by using various human epithelial cell lines (21-27). Since there is little or no information available on pesticide-induced breast cancer, an in vitro breast transformation model provides an opportunity for studying breast carcinogenesis.

The aim of the present study was to identify the differentially expressed human drug metabolism genes encoding enzymes that are important to drug transport and metabolism in an immortalized human breast epithelial cell line, MCF-10F (21) treated with parathion and estrogen, either alone or in combination by using cDNA microarrays.

\section{Materials and methods}

Cells. The MCF-10F cells were used in their 41st passage. Cells were cultured with DMEM/F-12 (1:1) medium supplemented with antibiotics $[100 \mathrm{U} / \mathrm{ml}$ penicillin, $100 \mu \mathrm{g} /$ $\mathrm{ml}$ streptomycin, $2.5 \mu \mathrm{g} / \mathrm{ml}$ amphotericin B, (all from Life Technologies, Grand Island, NY)] and $10 \mu \mathrm{g} / \mathrm{ml}$ and $5 \%$ equine serum (Biofluids, Rockville, MD), $0.5 \mu \mathrm{g} / \mathrm{ml}$ hydrocortisone (Sigma, St. Louis, MO) and $0.02 \mu \mathrm{g} / \mathrm{ml}$ epidermal growth factor (Collaborative Research, Bedford, MA) were added. The cells used in these experiments were: i) control MCF-10F, ii) MCF-10F cells continuously treated with parathion at $100 \mathrm{ng} / \mathrm{ml}$ (parathion-ethyl) (SigmaAldrich, St. Louis, MO) for 20 passages, iii) MCF-10F continuously treated with estrogen at $10^{-8} \mathrm{M}$ (E2) (SigmaAldrich) and iv) the combination of both.

Isolation and purification of total RNA and mRNA. Total RNA was isolated from both the control MCF-10F and treated cells with Trizol reagent (Invitrogen Corp., Long Island, NY). Each sample comprising $500 \mu \mathrm{g}$ of total RNA was treated with $5 \mu \mathrm{l}$ of DNase I (10 U/ $\mu \mathrm{l})$ (Roche Pharm., Indianapolis, IN) for $60 \mathrm{~min}$ at $37^{\circ} \mathrm{C}$. Then $10 \mathrm{X}$ Termination Mix (0.1 M EDTA, pH 8.0 and $1 \mathrm{mg} / \mathrm{ml}$ glycogen) (Clontech, CA) was used to stop the reaction. Each sample was then purified following established procedures (28). The purified RNA sample was first measured by a spectro- photometer (the ratio of absorbance reading at $260 \mathrm{~nm} /$ $280 \mathrm{~nm}$ at least 1.8) and then electrophoresed on denaturing formaldehyde/agarose/ethidium bromide gel. Each sample of $500 \mu \mathrm{g}$ of purified total RNA was then subjected to poly ${ }^{+}$ RNA analysis with the Oligotex mRNA Purification kit (Qiagen Inc., Valencia, CA). PolyA ${ }^{+}$RNA was then purified following the established procedure (28).

cDNA expression array. The GE Array Q Series Human Drug Metabolism Gene Array includes genes that encode enzymes important for Drug Transport, Phase I metabolism, and Phase II metabolism (SuperArray, Bethesda, MD). It is designed to profile gene expression of a panel of $96 \mathrm{key}$ genes associated with drug metabolism. The purified mRNAs were used for the synthesis of cDNA probes with Biotin-16dUTP (Roche Pharm.). Annealing mixture was prepared by mixing $\sim 1.0-5.0 \mu \mathrm{g}$ of mRNA with $3 \mu \mathrm{l}$ of Buffer A (GE primer mix) (SuperArray), and the final volume was adjusted to $10 \mu 1$. The mixture was then incubated in a preheated thermal cycler at $70^{\circ} \mathrm{C}$ for $3 \mathrm{~min}$, cooled to $42^{\circ} \mathrm{C}$ and kept at that temperature for $2 \mathrm{~min}$. Then $10 \mu \mathrm{l}$ of RT cocktail was prepared by mixing $4 \mu \mathrm{l}$ of $5 \mathrm{X}$ Buffer BN [for $50 \mu \mathrm{l} 10 \mathrm{X}$ Buffer, we added $1 \mu 1$ of $1 \mathrm{M}$ DTT and $50 \mu 1$ of $10 \mathrm{X}$ dNTP mix (5 mM dATP, dCTP, dGTP and $500 \mu \mathrm{M}$ dTTP)], $2 \mu 1$ of Biotin-16-dUTP, $2 \mu 1$ of RNase-free $\mathrm{H}_{2} \mathrm{O}, 1 \mu \mathrm{l}$ of RNase Inhibitor (Promega Corp., Madison, WI) and $1 \mu 1$ of MMLV Reverse Transcriptase (Promega Corp.). The RT cocktail was then warmed at $42^{\circ} \mathrm{C}$ for $1 \mathrm{~min}$ and slowly mixed with $10 \mu \mathrm{l}$ of pre-warmed annealing mixture. Incubation was continued at $42^{\circ} \mathrm{C}$ for $90 \mathrm{~min}$, and then the labeled cDNA probe was denatured by heating at $94^{\circ} \mathrm{C}$ for $5 \mathrm{~min}$, and quickly chilled on ice. cDNA probes were prepared from each one and hybridized to the respective membranes. Experiments using the same mRNA preparation were repeated two or three times, and measurable median-normalized expression values of each gene were compared to avoid false-positive signals (29). Each array membrane was pre-wetted with $5 \mathrm{ml}$ of deionized water and incubated at $60^{\circ} \mathrm{C}$ for $5 \mathrm{~min}$. It was then replaced with $2 \mathrm{ml}$ of pre-warmed $\left(60^{\circ} \mathrm{C}\right)$ GEAprehyb solution (GEAhyb solution with a heat-denatured sheared salmon sperm DNA at a final concentration of $100 \mu \mathrm{g} / \mathrm{ml}$ ) (SuperArray) and mixed gently for a few sec. Prehybridization was continued at $60^{\circ} \mathrm{C}$ for 1 to $2 \mathrm{~h}$ with continuous gentle agitation. An approximate $0.75 \mathrm{ml}$ solution of GEAhyb was prepared by adding the entire volume of denatured cDNA probe into the GEAprehyb solution and kept at $60^{\circ} \mathrm{C}$. Then the GEAprehyb solution was replaced by GEAhyb solution and incubation was continued overnight and hybridization at $60^{\circ} \mathrm{C}$ with continuous gentle agitation. Subsequently, array membranes were washed twice in wash solution 1 ( $2 \mathrm{X}$ sodium chloride sodium citrate and $1 \%$ sodium dodecyl sulfate) at $60^{\circ} \mathrm{C}$ for 15 min each time with gentle agitation and then washed twice with solution $2(0.1 \mathrm{X}$ sodium chloride sodium citrate and $0.5 \%$ sodium dodecyl sulfate) at $60^{\circ} \mathrm{C}$ for 15 min each time with gentle agitation.

Chemiluminescent detection of cDNA probes. After discarding the last wash, $2 \mathrm{ml}$ of GEAblocking solution was added to each membrane and incubated for $40 \mathrm{~min}$ at room temperature with continuous agitation. Then the binding buffer was 
prepared by diluting alkaline phosphatase-conjugated streptavidin (AP) with $1 \mathrm{X}$ Buffer F (SuperArray) in a 1:7500 dilution. GEAblocking solution was replaced by $2 \mathrm{ml}$ of binding buffer and incubated for 10 min with continuous but gentle agitation. Then the membrane was washed 4 times with $4 \mathrm{ml}$ of $1 \mathrm{X}$ binding Buffer $\mathrm{F}$ for 5 min each washing and rinsed twice with $3 \mathrm{ml}$ of rinsing Buffer $\mathrm{G}$. Then the membrane was covered with $1.0 \mathrm{ml}$ of CDP-Star chemiluminescent substrate to incubate at room temperature for 2 to $5 \mathrm{~min}$. It was then exposed to X-ray film (Kodak BioMax MS Film; Kodak Corp., Rochester, NY) with a corresponding intensifying screen at room temperature for multiple exposures of 1-5 min. Quantification of hybridization signals on the expression array membranes was carried out by exposing the autoradiographic film in a densitometric scanner (model 300A; Molecular Dynamics, Sunnyvale, CA), and then estimated both with the ImageQuant (Molecular Dynamics) and ScanAnalyzer program (Eisen Lab, Lawrence Berkeley National Lab). Volume quantification was performed by calculating the volume under the surface created by a threedimensional plot of pixel locations and pixel values as described (29,30). All raw signal intensities were corrected for background by subtracting the signal intensity of a negative control or blank. They were also normalized to that of a housekeeping gene. These signals were used to estimate the relative abundance of particular transcripts. To delineate the potential signal interference between adjacent strong hybridization signals, equal-sized ellipses were drawn around each signal area (hybridization spots) by using the software ImageQuant/ScanAnalyzer and were then separately scanned and compared with housekeeping genes so the chances of interference between adjacent strong hybridization signals were minimized. Normalization of the expression levels of different housekeeping genes from multiple autoradiographic exposures between different hybridization experiments was conducted by taking the average signals of each of the housekeeping genes. Data from the concentration spots $\geq 2.5$-fold versus control were used. The median background was subtracted and signals that were $<2.5$-fold were considered too low to accurately measure and were omitted from the analysis. Signals for each individual gene were also normalized to the geometric mean of the expression level of that gene across the set of membranes being compared. Mean signals were calculated from quadruplicate measurable spots, or if three of the four spots were measurable. Then the change in fold indicated whether a gene exhibited increased, decreased, or unchanged expression, based on statistical criteria (30).

\section{Results}

Expression of drug metabolism genes in the parental MCF-10F and transformed cells induced by the various treatments was ascertained using a human drug metabolism gene array. $\mathrm{MCF}-10 \mathrm{~F}$ cells treated with parathion, E2, and parathion plus E2 in comparison to the control MCF-10F were studied to analyze the expression profile of 96 genes involved in human drug metabolism regulation. The origin and phenotypic characteristics of cells used in these studies are shown in Table I. The parental MCF-10F cell line was treated with
1 8 1 8
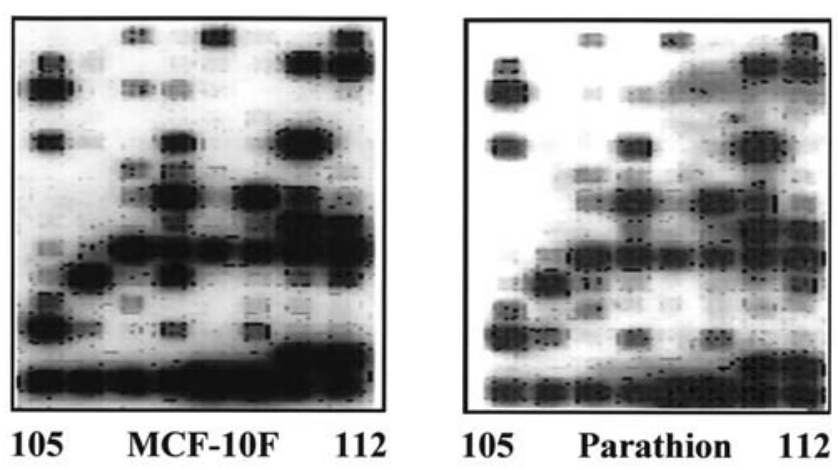

1 8 1 8

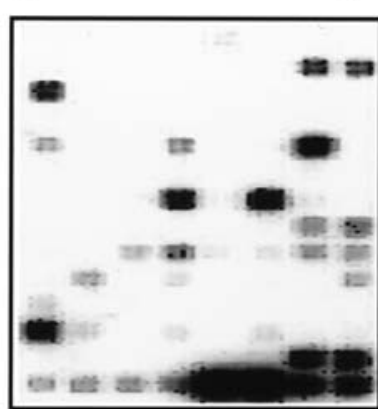

105
E2

\section{2}

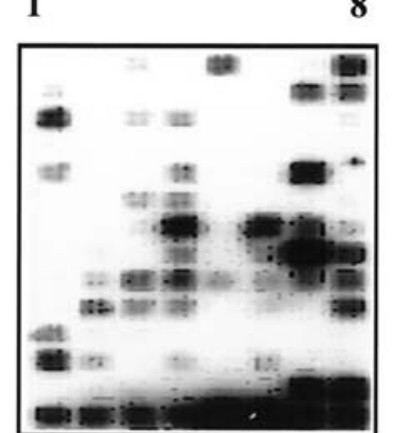

105 Parathion+E2 112
Figure 1. Human Drug Metabolism Gene Array. Differentially expressed genes of human drug metabolism in the parental MCF-10F (top left), MCF$10 \mathrm{~F}$ plus parathion (top right), MCF-10F plus estrogen (E2) (bottom left) and MCF-10F plus parathion and E2 (bottom right) cells.

parathion, E2, and the combination of parathion and E2 for 20 passages in culture. The anchorage independence capability of treated cells was analyzed. MCF-10F cells did not form colonies in agar, and colony-forming efficiency scored 21 days after plating in agar fluctuated from $1-3 \%$ in the presence of parathion, E2, and the combination of both $(31,32)$. The invasive characteristics of the control and treated MCF-10F cells were scored $20 \mathrm{~h}$ after plating onto matrigel basement membranes using Boyden's chambers. The control MCF-10F cell line and E2-treated cells showed no invasive capabilities, and there was no significant difference between these two groups. Addition of parathion to the growth medium enhanced the invasive phenotype of cells in comparison to the control and E2-treated cells. Cells treated with parathion alone and parathion combined with E2 had greater invasive capability than the control MCF-10F and E2-treated cells. However, no significant difference was observed between the cells treated with parathion alone and the cells treated with parathion combined with E2 $(31,32)$.

Results indicated that among the various human drug metabolism genes present in the array, 17 genes were altered either by parathion, E2, or the combination of both as seen in Fig. 1 and Table IIA and B. The functional gene groups altered by the effect of the pesticide and E2 were sulfotransferases, cytochromes P450 (CYPs) (subfamily IIF polypeptide 1 , subfamily IIIA polypeptide 7 , subfamily IVF polypeptide 3), glutathione S-transferases (GSTs), metallo- 
Table I. Origin and phenotypic characteristics of the cell lines.

\begin{tabular}{lllc}
\hline Cells & \multicolumn{1}{c}{ Origin } & AIA & IA \\
\hline MCF-10F & MCF-10F parental cells & - & - \\
Parathion $^{\mathrm{a}}$ & MCF-10F treated with parathion & + & + \\
${\text { Estrogen }(\mathrm{E} 2)^{\mathrm{b}}}^{\text {Parathion }+\mathrm{E} 2^{\mathrm{c}}}$ & MCF-10F treated with estrogen & - & - \\
\hline
\end{tabular}

MCF-10F cells were treated with ${ }^{\mathrm{a}} 100 \mathrm{mg} / \mathrm{ml}$ parathion during 20 passages; bestrogen $\left(10^{-8} \mathrm{M}\right)$ (E2) during 20 passages; and ${ }^{\mathrm{c}}$ combination of parathion and E2 for 20 passages. AIA, Anchorage independence colony-forming efficiency in soft agar. IA, Invasion assay; invasive characteristics of the control and MCF-10F-treated cells scored $20 \mathrm{~h}$ after plating onto matrigel basement membranes using Boyden's chambers. +, The results in relation to anchorage independent growth and number of cells that crossed the filters; -, lack of anchorage independent growth and invasiveness.

Table II. Human drug metabolism genes.

A

\begin{tabular}{|c|c|c|c|c|c|}
\hline Position in array & Name & Symbol & E2 & $\mathrm{P}$ & $\mathrm{P}+\mathrm{E} 2$ \\
\hline 15 & $\begin{array}{l}\text { Carbohydrate (N-acetylglucosamine 6-0) } \\
\text { sulphotransferase } 5\end{array}$ & CHST5 & $\downarrow$ & $\uparrow$ & $\downarrow$ \\
\hline 16 & $\begin{array}{l}\text { Carbohydrate (N-acetylglucosamine } 6-0) \\
\text { sulphotransferase } 6\end{array}$ & CHST6 & $\downarrow$ & $\uparrow$ & $\downarrow$ \\
\hline 17 & $\begin{array}{l}\text { Carbohydrate (N-acetylglucosamine 6-0) } \\
\text { sulphotransferase } 7\end{array}$ & CHST7 & $\downarrow$ & $\uparrow$ & $\downarrow$ \\
\hline 33 & Cytochrome P450, subfamily IIF, polypeptide 1 & CYP2F1 & $\downarrow$ & $\uparrow$ & $\downarrow$ \\
\hline 36 & Cytochrome P450, subfamily IIIA, polypeptide 7 & CYP3A7 & $\downarrow$ & $\uparrow$ & $(-)$ \\
\hline 39 & Cytochrome P450, subfamily IVF, polypeptide 3 & CYP4F3 & $\downarrow$ & $\uparrow$ & $\downarrow$ \\
\hline 52 & Glutathione $S$-transferase $\pi 1$ & GSTP1 & $\downarrow$ & $\uparrow$ & $(-)$ \\
\hline 54 & Glutathione S-transferase $\theta 2$ & GSTT2 & $\downarrow$ & $\uparrow$ & $(-)$ \\
\hline 63 & Glutathione S-transferase microsomal & MGST1 & $\downarrow$ & $\uparrow$ & $\downarrow$ \\
\hline
\end{tabular}

B

\begin{tabular}{|c|c|c|c|c|c|}
\hline Position in array & Name & Symbol & E2 & $\mathrm{P}$ & $\mathrm{P}+\mathrm{E} 2$ \\
\hline 67 & Metallothionein 1A (functional) & MT1A & $\downarrow$ & $(-)$ & $\downarrow$ \\
\hline 68 & Metallothionein IE (functional) & MT1E & $\downarrow$ & $(-)$ & $\downarrow$ \\
\hline 69 & Metallothionein $1 \mathrm{G}$ & MT1G & $\downarrow$ & $(-)$ & $\downarrow$ \\
\hline 70 & Metallothionein $1 \mathrm{H}$ & MT1H & $\downarrow$ & $(-)$ & $\downarrow$ \\
\hline 71 & Metallothionein 1L & MT1L & $\downarrow$ & $(-)$ & $\downarrow$ \\
\hline 72 & Metallothionein 2A & MT2A & $\downarrow$ & $(-)$ & $\downarrow$ \\
\hline 74 & Metallothionein IX & MTIX & $\downarrow$ & $\uparrow$ & $\downarrow$ \\
\hline 89 & Thiopurine S-methyltransferase & TPMT & $\downarrow$ & $\uparrow$ & $\downarrow$ \\
\hline 92 & UDP glycosyltransferase 1 family, polypeptide Al & UGT1A1 & $\downarrow$ & $\uparrow$ & $(-)$ \\
\hline 94 & UDP glycosyltransferaee 2 family, polypeptide B & UGT2B & $\downarrow$ & $\uparrow$ & $(-)$ \\
\hline
\end{tabular}

$\uparrow$ Up-regulated expression; $\downarrow$ down-regulated expression; (-) no change in expression of that gene with respect to the control MCF-10F. Note, both up-regulation and down-regulation of gene expression over 2.5- to 5-fold alterations were taken into consideration. P, parathion; E2, estrogen. 
thioneins (MTs), methyltransferase and UDP glycosyltransferases.

Among the genes altered by parathion in comparison to control were CHST5, CHST6 and CHST7 (sulfotransferases); CYP2F1, CYP3A7 and CYP4F3 (CYPs); GSTP1, GSTT2 and MGST1 (GSTs); MT1X (metallothionein); TPMT (methyltransferase); UGT1A1 and UGT2B (UDP glycosyltransferases). The enzyme gene expression was 2.5- to 5fold up-regulated in the parathion-treated group in comparison to the control. The same genes were 2.5- to 5-fold down-regulated in E2 alone including several metallothioneins (MT1A, MT1E, MT1H, MT1L and MT2A). The combination of parathion and E2 induced down-regulation of three sulfotransferases, CYP2F1 and CYP4F3, MGST1, all metallothioneins and TPMT genes. There was no change in CYP3A7, GSTP1, GSTT2, UGT1A1 and UGT2B genes in the presence of both substances.

\section{Discussion}

Differentially expressed drug metabolism genes were evaluated in parathion- and E2-in vitro-transformed breast cells. Pesticides are currently used to improve agricultural production (5-8). However, insecticides have been classified as carcinogens by the International Agency for Research on Cancer in humans (33-35). The human data are limited due to the restricted number of studies examining individual pesticides. However, the human population is exposed not only to pesticides but also to a mixture of estrogenic or estrogen-like agents. Epidemiological and experimental evidence has implicated estrogens in the etiology of breast cancer (33-35). It is known that estrogens are associated with carcinogenic events in both humans and animals $(36,37)$.

The effect of estrogens in breast cancer remains unclear. Molecular biomarkers are essential to analyze the progression of breast cancer and to identify genes involved in the process of neoplastic transformation induced by several agents, among which pesticides and E2 are very important. The present study analyzed the presence of several molecular biomarkers in a simple array by using transformed cells. Experimental studies have demonstrated that mammary cancer is a hormone-dependent multi-step process that can be induced by a variety of compounds and mechanisms. Therefore, it is necessary to consider the impact of combined effects of both pesticides and estrogens. In vivo and in vitro experimental models are needed in order to understand the effects of these compounds in breast carcinogenesis. Previous studies $(31,32)$ in vitro showed that parathion and E2 alone and the combination of both were capable of altering cell proliferation and inducing transformation of the MCF-10F cell line. The increase in cell proliferation rate indicated by a shorter doubling time, anchorage independent growth and in vitro invasive capability suggest a very aggressive phenotype. Treatment of parathion alone or its combination with E2 exhibited significant invasive capabilities as compared to the control cells.

Molecular biomarkers of Phase II enzymes have been studied in relation to the risk of cancer. Cytosolic sulfotransferase enzymes catalyze the sulfation of a large variety of drugs and endogenous substances. Results indicated that
CHST5, CHST6 and CHST7 (sulfotransferase) genes were up-regulated by parathion and down-regulated by E2. The combination of parathion and E2 induced down-regulation of three sulfotransferase genes. A high frequency of SULT1A1 has been identified in patients with breast cancer (18).

Expression of several CYP genes was up-regulated by the effect of parathion whereas the same genes were downregulated in the presence of $\mathrm{E} 2$ alone. The combination of parathion and E2 induced down-regulation of CYP2F1 and CYP4F3. There was no change in the CYP3A7 gene in the presence of both substances. These changes suggest that these substances may also have the potency to cause malignant transformation of breast epithelial cells through modulation of expression of such genes. It has been previously reported that the CYPs play a critical role in the oxidative metabolism activation and detoxification of a variety of endogenous and exogenous compounds influencing the biological effects of estrogens.

DNA damage by steroidal estrogens via catechol estrogen metabolites has been reported in relation to the carcinogenic activity of 4-hydroxyestradiol (4-CE), comparable to that of E2 in the hamster kidney tumor model (36-40). The 2hydroxylation (2-CE) of steroidal estrogens is the major metabolic oxidation of estrogenic hormones in most mammalian species (41-43). Such oxidation was catalyzed in the human or hamster liver by cytochrome P450 3A4 enzymes (42-49), whereas cytochrome P450 1A1 enzymes are the predominant estrogen 2-hydroxylases in extrahepatic tissues (44-47). In humans, the predominant conversion of E2 to 4$\mathrm{CE}$ has been detected in benign and malignant mammary tumors and normal mammary tissue (40). The human estrogen-4-hydroxylase activity has been identified as cytochrome P450 1B1, a novel extrahepatic isozyme detected specifically in mammary tissue, ovary, adrenal gland, uterus and several other tissues (48-50).

These studies showed that GST enzymes, such as the GSTP1, GSTT2 and MGST1 genes were up-regulated in the parathion-treated cells and down-regulated in the E2-treated group in comparison to the control. The combination of parathion and E2 induced down-regulation of three MGST1 genes. There was no change in the GSTP1 and GSTT2 genes in the presence of both substances. Nascimiento et al (16) and Rebbeck (17) have indicated an association between genotypes of Phase II enzymes and cancer risk by epidemiological studies. The molecular epidemiology of the human glutathione S-transferase genotypes GSTM1 and GSTT1 has indicated cancer susceptibility (17). A possible influence of the glutathione S-transferase GSTTI null genotype on the age of onset of sporadic colorectal adenocarcinoma has been reported (16). The high frequency of the GSTTI null genotype in patients diagnosed before the age of 60 years suggested that this genotype influences the age of disease onset. Variant alleles in GST, UDP glucuronosyltransferase (UGT) have been used as molecular genetic biomarkers of risk. The GSTM $\mu 1$ has been associated with an increased risk of colorectal cancer, lung cancer, bladder cancer and GSTP $\pi 1$ with prostate cancer.

Notably, the only functional gene altered by the effect of parathion among the metallothioneins was metallothionein $1 \mathrm{X}$. Its gene expression was up-regulated by parathion in 
comparison to the control whereas the same gene was downregulated in E2 alone and in the presence of the combination of both. However, it has only been previously reported that metallothionein $2 \mathrm{~A}$ expression is associated with cell proliferation in breast cancer (14).

Conjugation with UDP (uridindiphosphate) by UGT (glucuronidation) is one of the major routes of elimination and detoxification of drugs and endogenous compounds. Carcinogens and their reactive metabolites may also be glucuronidated to harmless intermediates that can be eliminated from the body. The UGT1A1 and UGT2B genes were up-regulated by parathion and down-regulated by E2. However, the combination of parathion and E2 induced no change in these genes. Dalhoff et al (18) have identified clinical studies using molecular genetic biomarkers of Phase II enzymes as markers of susceptibility to the development of cancer since UGT1A1 and UGT2B were increased in ovarian cancer. Therefore, the UGT1A1 and UGT2B genes seem to be reliable molecular biomarkers for the risk of cancer. It can be concluded from this study that organophosphorous pesticides such as parathion in the presence of estradiol induce changes in human drug metabolism gene expression in breast cells such as sulfotransferases, cytochromes P450, glutathione S-transferases, metallothioneins, and methyltransferase.

\section{Acknowledgements}

We sincerely thank Carlos Echiburú-Chau for his valuable criticism, Dr Tom K. Hei for his constant encouragement and Danissa Barahona for her secretarial assistance. The support from the grants from FONDECYT \#1040300 (G.M.C.) and CIHDE \#BIP20185093 is sincerely appreciated. D.R. has utilized the CUNY research release time to porform this study.

\section{References}

1. Davis DL, Axelrod D, Bailey L, Gaynor M and Sasco AJ: Rethinking breast cancer risk and the environment: the case for the precautionary principle. Environ Health Perspect 106: 523-529, 1998.

2. Krieger N: Exposure, susceptibility and breast cancer risk: a hypothesis regarding exogenous carcinogens, breast tissue development, and social gradients, including black/white differences, in breast cancer incidence. Breast Cancer Res Treat 13: 205-223, 1989.

3. Perera FP: Environment and cancer: who are susceptible? Science 278: 1068-1073, 1997.

4. Kelsey JL, Gammon MD and John EM: Reproductive factors in breast cancer. Epidemiol Rev 15: 36-47, 1993.

5. Klaasen C: Nonmetallic environmental toxicants: air pollutants, solvents and vapors, and pesticides. In: The Pharmacological Basis of Therapeutics. Goodman Gilman A, Rall TW, Nies AS and Taylor P (eds). Pergamon Press Inc, New York, pp1615-1635, 1990.

6. Falck A Jr, Ricci A Jr, Wolff MS, Godbold J and Deckers P: Pesticides and polychlorinated biphenyl residues in human breast lipids and their relation to breast cancer. Arch Environ Health 47: 143-146, 1992.

7. National Cancer Institute: Bioassay of malathion for possible carcinogenicity. Technical Report Series No. 24. DHEW Publication No. (NIH) 78-824, 1978.

8. Dick J, Zahm SH, Hanberg A and Adami HO: Pesticides and cancer. Cancer Causes Control 8: 420-443, 1997.

9. Kelsey JL and Bernstein L: Epidemiology and prevention of breast cancer. Annu Rev Public Health 17: 47-67, 1996.
10. Henderson BE, Ross R and Bernstein L: Estrogen as a cause of human cancer. The Richard and Hinda Rosenthal Foundations Award Lecture. Cancer Res 48: 246-253, 1988.

11. Bernstein L and Ross RK: Endogenous hormones and breast cancer risk. Epidemiol Rev: 15: 48-65, 1993.

12. Pike MC, Spicer DV, Dahmoush L and Press MF: Estrogens, progestogens, normal breast cell proliferation, and breast cancer risk. Epidemiol Rev 15: 17-35, 1993.

13. Dickson RB and Lipman MF: Control of human breast cancer by estrogen, growth factors and oncogenes. In: Breast Cancer: Cellular and Molecular Biology. Kluwer Academic Nonwell, MA, pp119-166, 1988.

14. Jin R, Chow VT, Tan PH, Dheen ST, Duan W and Bay BH: Metallothionein 2A expression is associated with cell proliferation in breast cancer. Carcinogenesis 23: 81-86, 2002.

15. Bauer M, Herbarth, Aust G and Graebsch C: Molecular cloning and expression of novel alternatively spliced cytochrome P450 2E1 mRNAs in humans. Mol Cell Biochem 280: 201-207, 2005.

16. Nascimiento H, Coy CS, Teori MT, Boin IF, Goes JR, Costa LL and Lima CS: Possible influence of glutathione S-transferases GSTTI null genotype on age of onset of sporadic colorectal adenocarcinoma. Dis Colon Rectum 46: 510-515, 2003.

17. Rebbeck TR: Molecular epidemiology of the human glutathione S-transferase genotypes GSTM1 and GSTT1 in cancer susceptibility. Cancer Epidemiol Biomarkers Prev 6: 733-743, 1997.

18. Dalhoff K, Buus Jensen K and Enghusen Poulsen H: Cancer and molecular markers of phase II. Methods Enzymol 400: 618-627, 2005.

19. Rebbeck TR: Molecular epidemiology of the human glutathione S-transferase genotypes GSTM1 and GSTT1 in cancer susceptibility. Cancer Epidemiol Biomarkers Prev 6: 733-743, 1997.

20. Cabello G, Valenzuela M, Vilaxa A, Durán V, Rudolph I, Hrepic N and Calaf G: A rat mammary tumor model induced by the organophosphorous pestides parathion and malathion, possibly through acetylcholinesterase inhibition. Environ Health Perspect 109: 471-479, 2001.

21. Calaf GM, Parra E and Garrido F: Cell proliferation and tumor formation induced by eserine, an acetyl-cholinesterase inhibitor in rat mammary gland. Oncol Rep 17: 25-33, 2007.

22. Soule HD, Maloney TM, Wolman SR, Peterson WD Jr, Brenz R, McGrath CM, Russo J, Pauley RJ, Jones RF and Brooks SC: Isolation and characterization of a spontaneously immortalized human breast epithelial cell line. MCF-10F. Cancer Res 50: 6075-6086, 1990 .

23. Thraves PJ, Salehi Z, Dristchilo A and Rhim JS: Neoplastic transformation of immortalized human epidermal keratinocytes by ionizing radiation. Proc Natl Acad Sci USA 87: 1174-1177, 1990.

24. Rhim JS and Dritschilo A (eds): Neoplastic transformation in human cell systems - An overview. In: Neoplastic Transformation in Human Cell Culture: Mechanisms of Carcinogenesis. Human Press Totowa, NJ, pp11-31, 1993.

25. Hei TK, Piao CQ, Willey JC, Thomas S and Hall EJ: Malignant transformation of human bronchial epithelial cells by radonsimulated $\alpha$ particles. Carcinogenesis 15: 431-437, 1994.

26. Riches AC, Herceg Z, Bryant PE and Wynford-Thomas D: Radiation-induced transformation of SV40-immortalized human thyroid epithelial cells by single and fractionated exposure to gamma-irradiation in vitro. Int J Radiat Biol 66: 757-765, 1994.

27. Calaf G and Russo J: Transformation of human breast epithelial cells by chemical carcinogens. Carcinogenesis 14: 483-492, 1993.

28. Calaf $\mathrm{G}$ and Hei TK: Establishment of a radiation- and estrogeninduced breast cancer. Carcinogenesis 21: 769-776, 2000.

29. Sambrook J, Fritsch EF and Maniatis T: Molecular Cloning. A Laboratory Manual. Cold Spring Harbor Laboratory Press, Cold Spring Harbor, NY, 1989.

30. Roy D, Calaf GM and Hei TK: Profiling of differentially expressed genes induced by high-LET radiation in breast epithelial cells. Mol Carcinog 31: 192-203, 2001.

31. Lui WM, Mei R, Di X, Ryder TB, Hubbell E, Dee S, Webster TA, Harrington CA, Ho MH, Baid J and Smeekens SP: Analysis of high density expression microarrays with signed-rank call algorithms. Bioinformatics 18: 1596-1599, 2002.

32. Calaf GM and Roy D: Gene expression signature of parathiontransformed human breast epithelial cells. Int J Mol Med 19: 741-750, 2007. 
33. Calaf GM and Roy D: Gene and protein expressions induced by $17 \mathrm{~B}$ estradiol and parathion in cultured breast epithelial cells. Mol Med 13: 255-265, 2007.

34. International Agency for Research on Cancer: Monographs on the Evaluation of Carcinogenic Risks to Humans. IARC Scientific Publications No. 21, IARC, Lyon, pp279-362, 1979.

35. International Agency for Research on Cancer: Monographs on the Evolution of Carcinogenic Risks to Humans. Suppl 7. IARC, Lyon, pp280-285, 1987.

36. International Agency for Research on Cancer: Monographs on the Evolution of Carcinogenic Risks to Humans: Hormonal Contraception and Postmenopausal Hormone Therapy. Vol. 72. IARC, Lyon, 1999.

37. Kirkman H: Estrogen-induced tumors of the kidney. III. Growth characteristics in the Syrian hamster. Natl Cancer Inst Monogr 1: 1-57, 1959.

38. Li J, Li SA, Klicka JK, Parsons JA and Lam LKT: Relative carcinogenic activity of various synthetic and natural estrogens in the Syrian hamster kidney. Cancer Res 43: 5200-5204, 1983.

39. Li JJ and Li SA: Estrogen carcinogenesis in hamster tissues: role of metabolism. Fed Proc 46: 1858-1863, 1987.

40. Liehr JG, Fang WF, Sirbasku DA and Ari-Ulubelen A: Carcinogenicity of catechol estrogens in Syrian hamsters. J Steroid Biochem 24: 353-356, 1986.

41. Liehr JG and Ricci MJ: 4-Hydroxylation of estrogens as marker of human mammary tumors. Proc Natl Acad Sci USA 93: 3294-3296, 1996.

42. Zhu BT and Conney AH: Functional role of estrogen metabolism in target cells: Review and perspectives. Carcinogenesis 19: $1-27,1998$.

43. Slaunwhite WR, Kirdani RY and Sandberg AA: Metabolic aspects of estrogens in man. In: Handbook of Physiology, Section 7, Part 1, Endocrinology. Greep RO, Astwood EB and Geiger SR (eds). American Physiological Society, Washington, DC, 1973 .
44. Martucci C and Fishman J: P450 enzymes of estrogen metabolism. Pharmacol Ther 57: 237-257, 1993.

45. Guengerich FP: Characterization of human microsomal cytochrome P450 enzymes. Annu Rev Pharmacol Toxicol 29: 241-264, 1989.

46. Aoyama T, Korzekwa K, Nagata K, Gillette J, Gelboin HV and Gonzalez FJ: Estradiol metabolism by complementary deoxyribonucleic acid-expressed human cytochrome. Endocrinology 126: 3101-3106, 1990.

47. Kerlan V, Dreano Y, Bercovici JP, Beaune PH, Floch HH and Berthou F: Nature of cytochrome P450 involved in the 2/4hydroxylation of estradiol in human liver microsomes. Biochem Pharmacol 44: 1745-1756, 1992.

48. Hammond DK, Zhu BT, Wang MY, Ricci MJ and Liehr JG: Cytochrome P450 metabolism of estrogen in hamster liver and kidney. Toxicol Appl Pharmacol 145: 54-60, 1997.

49. Hayes CL, Spink DC, Spink BC, Cao JQ, Walker NJ and Sutter TR: 17beta-estradiol hydroxylation catalyzed by human cytochrome P450 1B1. Proc Natl Acad Sci USA 93: 9776-9781, 1996.

50. Savas U, Bhattacharya KK, Christou M, Alexander DL and Jefcoate CR: Mouse cytochrome P-450EF, representative of a new 1B subfamily of cytochrome P-450s: cloning, sequence determination and tissue expression. J Biol Chem 269: 14905-14911, 1994

51. Sutter TR, Tang YM, Hayes CL, Wo Y-Y, Jabs EW, Li X, Yin H, Cody CW and Greenlee WF: Complete cDNA sequence of human dioxin-inducible mRNA identifies a new gene subfamily of cytochrome P450 that maps to chromosome 2. J Biol Chem 269: 13092-13099, 1994. 